\title{
Some Critical Discussions on Flash and Fire Points of Liquid Fuels
}

\author{
HIROKI ISHIDA and AKIRA IWAMA \\ Institute of Space and Astronautical Science \\ 4-6-1, Komaba, Meguro-ku, Tokyo, 153, Japan
}

Keywords: Pre-flash point, Flash point, Fire point, Vapor pressure, Lower

flammability limit, Raoult's law, Clausius-Clapeyron's law

\section{ABSTRACT}

The liquid fuel temperatures of the flash and fire points were discussed for their accurate measurement according to their definitions from the view point of spilled fuel fire hazard prevention. The flash and fire points for some hydrocarbon and alcohol fuels were measured at the open cup system with an electric spark ignition source, avolding the external air blow. Measured results were compared with those by the usual methods of Tag Closed Cup and Pensky-Martens, and some influencing factors in the measurement were discussed. In the present study, pre-flash phenomenon, namely "Pre-flash point", was found at a little lower liquid temperature than the flash point. It suggests that the specification of the scale of flame appearance at flash phenomenon above the fuel pool surface should be introduced in the usual methods of flash point measurement. Presented consideration on flash point covers the theoretical prediction of flash point of the binary hydrocarbon fuel mixture.

\section{RECENT PHASES OF THE STUDIES}

Many studies on the fire hazard prevention for liquid fuel have concentrated their serious interests to the flash point of the fuel for more than forty years. The flash point is defined as the fuel temperature at which the equilibrium fuel vapor concentration of its lower flammability limit is attained. It has been measured and investigated concerning such parameters as the latent heat of vaporization, the boiling temperature and the fuel vapor concentration of lower flammability limit for the purpose of theoretical prediction of the accurate fuel temperature when the flash phenomenon occurs (1-8). Many previous reports, however, have presented divergent measured values one another, which are due to complex parametric factors in their measuring apparatuses and methods for flash point such as the position and dimension of ignition source, mixing or no-mixing in vapor phase above pool, and fuel container condition (open or closed)(1-14).

Then, not all investigations in this field are, of course, necessarily complete, as discussed in detail by Glassman et al.(16). It seems that some unsolved problems remain still in the usual methods of flash point measurement for the purpose of obtaining the accurate flash point $(9,13-17)$. Although the fire point is defined as the lowest fuel temperature at which the diffusion flame is sustained above the fuel pool without any external heat supply $(7,19,20)$, generally reliable data have not been published. We can see the considerable

The present address for Hiroki Ishida is Dept. of Mechanical Eng., Nagaoka Technical Collede 888, Nishikatakai, Nagoaka, Niigata-pref., 940, Japan. 
divergence among the fire point data in some previous papers, and the divergence seems due to more complex parametric factors in the measuring methods which have significant effects on the measured result than in flash point measurement $(15-20)$.

\section{FAVORABLE MEASUREMENT OF FLASH AND FIRE POINTS}

The purpose of the present study is to obtain the accurate flash and fire points for some hydrocarbon and alcohol fuels under the experimental condition according to their definitions, and to examine the measured results comparing with those in previous studies for clarifying the influencing factors in the measurement. Although different apparatuses and methods give different measured values, it is necessarily important to know the accurate fuel temperatures at flash and fire phenomena according to their definitions for the detailed discussions in the problems of the flame spread mechanism along liquid fuel surface (15-18) and of the ignition behavior of fuel droplet in the hot atmosphere (2l-24) or on the hot solid surface $(25,26)$. The accurate measurements of these temperatures are impotant also for the estimation and classification of the flammability hazard of liquid fuels. Figures 1 and 2 show the relations between the equilibrium vapor pressure and liquid temperature for alcohol and hydrocarbon fuels respectively, where $\mathrm{T}$ indicates the theoretical flash point. The essentials in all the methods for flash point measurement exist in the accurate measurement of $\mathrm{T}_{\mathrm{fl}}$.

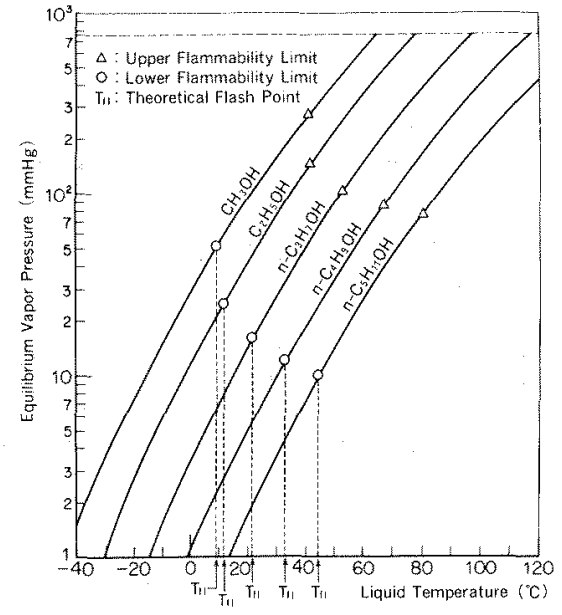

FIGURE 1



FIGURE 2

FIG.I and 2: The Relation between Equilibrium Vapor Pressure and Liquid

Fuel Temperature (from literature).

As predicted reasonably, there exists the boundary layer of fuel vapor concentration above liquid pool. Figure 3 shows the interferogram with He-Ne laser source (wave length; $6328 \AA$ ) and the concentration profile in the boundary layer of n-octane vapor above the liquid surface. Figure 3 shows that the equilibrium fuel vapor concentration adjacent to the pool surface agrees with that predicted from Fig.2. The result shown in Fig. 3 suggests also that the disturbance of fuel vapor diffusion has a significant effect on the production of flammable concentration zone above the pool surface and on the measured results of flash point. We can expect that measured flash point approaches to the theoretical value $T_{f l}$ even by the open cup method, if the ignition source is placed closely to the pool surface and disturbing air blow is prevented. Also the flash point is to be measured as higher value with increase of the distance between the ignition source and the pool surface $(6,16)$. 




FIG.3: Interferograms (a) and (b) of Concentration Boundary Layer, and Calculated Concentration Profile (c) above n-octane pool at $14^{\circ} \mathrm{C}$.

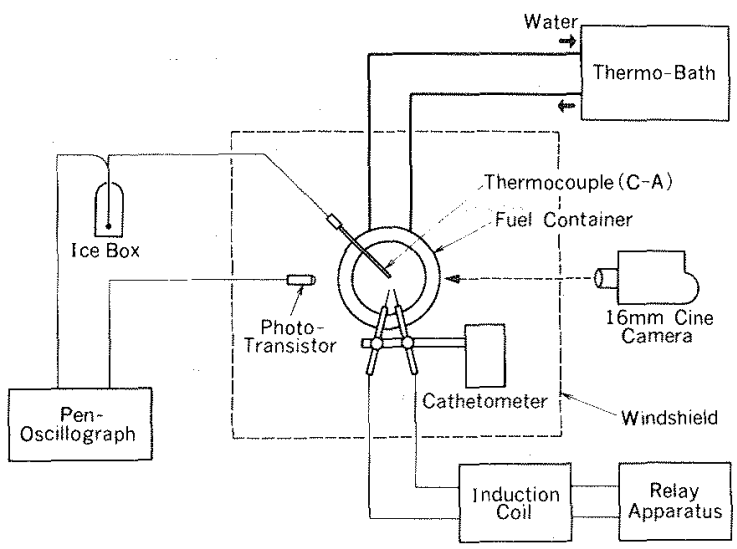

FIG.4: Schematic Drawing of The Measurement apparatus of Flash and Fire Points at Open Cup System with Electric Spark Ignition Source.
Figure 4 shows the measurement apparatus in the present study of flash and fire points with open cup and spark ignition source. The fuel was filled up to the lip level of the container cup (diameter $50 \mathrm{~mm}$, depth $20 \mathrm{~mm}$ ) and the fuel temperature was maintained constant by the temperature controlled cup. Phototransistor was used for the detection of flame when the flash phenomenon occurred , and thermocouple ( $C-A, 0.1 \mathrm{~mm}$ dia.) was taken for monitoring the fuel surface temperature. Spark electrode position above pool surface is accurately set at a height by a cathetometer, spark gap is $3 \mathrm{~mm}$, and spark duration was set at 0.3 sec by relay circuit apparatus. Then, spark ener gy, approximately 100-300 mJ generated by the induction coil, is sufficient as the ignition source. For avoiding the disturbance of fuel vapor diffusion by external air blow, most of measurement equipments were enclosed in the windshield with PMMA plates. $16 \mathrm{~mm}$ movie was taken for observing the aspect of flash phenomenon in detail.

\section{PRE-FLASH, FLASH AND FIRE PHENOM-} ENA

In the present study, typical hydrocarbons and alcohols of which flash points are not so far from the room temperature were chosen from the view point of accurate measurement in the experiment. The "pre-flash" phenomenon can be observed for some fuels at a little lower liquid temperature than the flash point. It is instantaneous and faint but clear propagating appearence of a flamelet, and is due to local flame propagation through the stratified fuel vapor layer adjacent to the pool surface.

Figure 5 shows the pre-flash phenomenon on the pool surface of $n$-nonane, where a propagating stretch of flamelet appears in the picture No,2. Pre-flash is clearly different from the flame appearance such as small blue "halo" 
of the burning fuel vapor which surrounds the pilot ignition flame as often observed in usual flash point measurements (e.g. Tag Closed Cup and Pensky-Martens methods), and such blue halo would not propagate across the pool surface.

Figures 6 and 7 show the flash and fire phenomena on the n-nonane pool respectively, which follow after the pre-flash. Flame propagation area above the pool surface in the flash is clearly larger than that in the pre-flash. Although the full interpretation of "pre-flash" phenomenon, especially the reason why the flamelet propagates locally only above some part of pool surface and why it is extinguished on the way, can not be given in the present stage of this study, we can consider some important factors as that the position of ignition source (spark electrode) is the center of fuel pool surface of the tray, and there must exist the considerable escape of generated fuel vapor by outer diffusion near the periphery of tray. Fire phenomenon was determined as the flame sustaining of at least five seconds above the pool after the flash phenomenon. In these figures, a generated spark is imaged by halation shown as the small bright point. Flash phenomenon is in itself the ignition and flame propagation in gas phase where the fuel vapor concentration gradient exists, and the flame propagates through only the thin stratified gas layer close to the pool surface (27-30).

Then, the scale of flame appearance on the pool surface should be specified additionally in the usual methods of flash point measurement. On the other hand, for alcohol fuels ( $n$-butanol and iso-butanol), such pre-flash and flash phenomena could not be observed. Glassman et al. also discussed the experimental result that the flash and fire phenomena occur at the same liquid temperature for alcohol fuels $(16)$.

Table 1 shows the fuel temperatures at which pre-flash, flash and fire phenomena occurred, with the relation to the height of spark electrode above fuel. surface. Table 2 shows the measured results of flash point by usual methods, Tag Closed Cup and Pensky-Martens methods, and theoretical flash point determined by the condition of lower flammability limit concentration on the curve of equilibrium vapor pressure. As shown in these tables, except alcohol fuel, the pre-flash point is $1-3^{\circ} \mathrm{C}$ lower than the flash point, and the fire point is $3-7^{\circ} \mathrm{C}$ higher than the flash point when the spark position is $3 \mathrm{~mm}$ above pool. For alcohol fuel, although it was very difficult to distinguish between flash and fire points in the present spark method, the fire point is, however, shown about $10{ }^{\circ} \mathrm{C}$ higher than the flash point by Tag Closed Cup method. For o-xylene, a bright flame and soot formation can be observed not only in the fire phenomenon but also even in the pre-flash and flash phenomena, which are usually observed for such fuels as aromatic compounds.

As evident from these tables, flash points by open cup method with spark ignition source are higher than those by Tag Closed Cup method. This is, as often discussed for closed cup method, due to the local heating of pool surface by small pilot ignition flame and the increase of air entrainment by the induced convection. On the other hand, fire points by the open cup method with spark ignition source are lower than those by Tag closed Cup method, which is probably because the air entrainment is sufficient at open cup system but poor at closed cup system.

The heights of small pilot ignition flame (about $4 \mathrm{~mm}$ dia.) above pool surface are specified as $27-29 \mathrm{~mm}$ in Tag Closed Cup method (ASTM D-56), 19-21 $\mathrm{mm}$ in Pensky-Martens method (ASTM D-93) and 9-11 mm in Cleaveland Open Cup method ( ASTM D-92). They are very higher than the positions of spark ignition source in the present study, but the thermal energy of spark ignition source is very smaller than that of pilot flame. Then, the effect of local heating of pool surface by spark and/or thermocouple can be neglected in the present study.

Pre-flash, falsh and fire points rise $1-3,2-5$ and $2-10{ }^{\circ} \mathrm{C}$ respectively with increase of the height of spark ignition source. When the height was lower than $3 \mathrm{~mm}$, it was often impossible to ignite the fuels in the present study. These results suggest lucidly that flash phenomenon occurs only when tne flammable mixture was produced around the ignition source, and the quenching layer above 


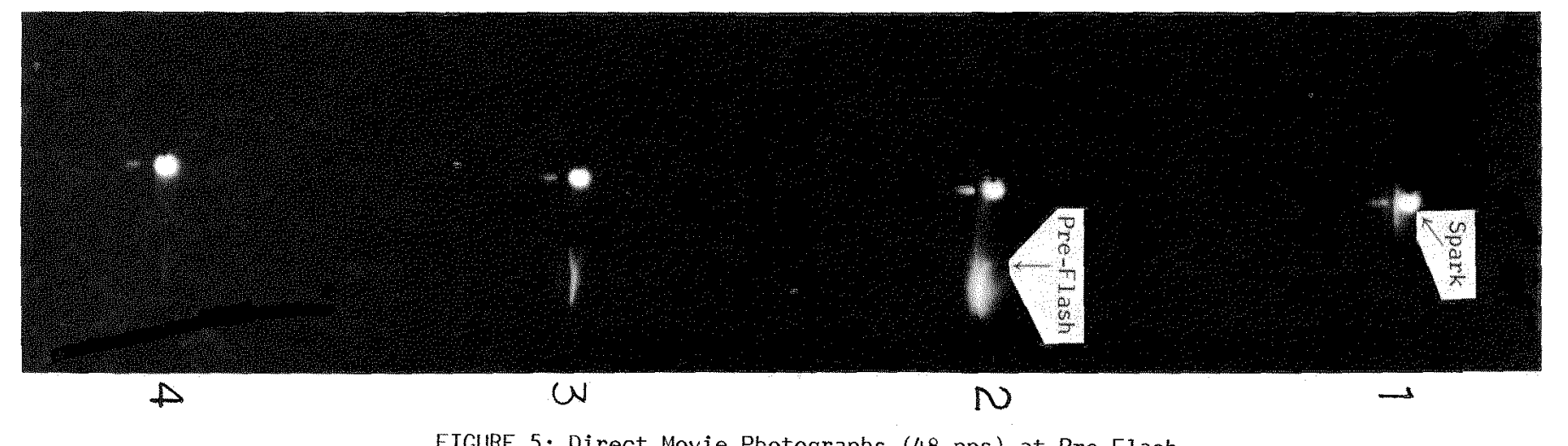

FIGURE 5: Direct Movie Photographs (48 pps) at Pre-Flash

Point $\left(37^{\circ} \mathrm{C}\right)$ of $n$-Nonane, Spark Position is $3 \mathrm{~mm}$ above Pool.

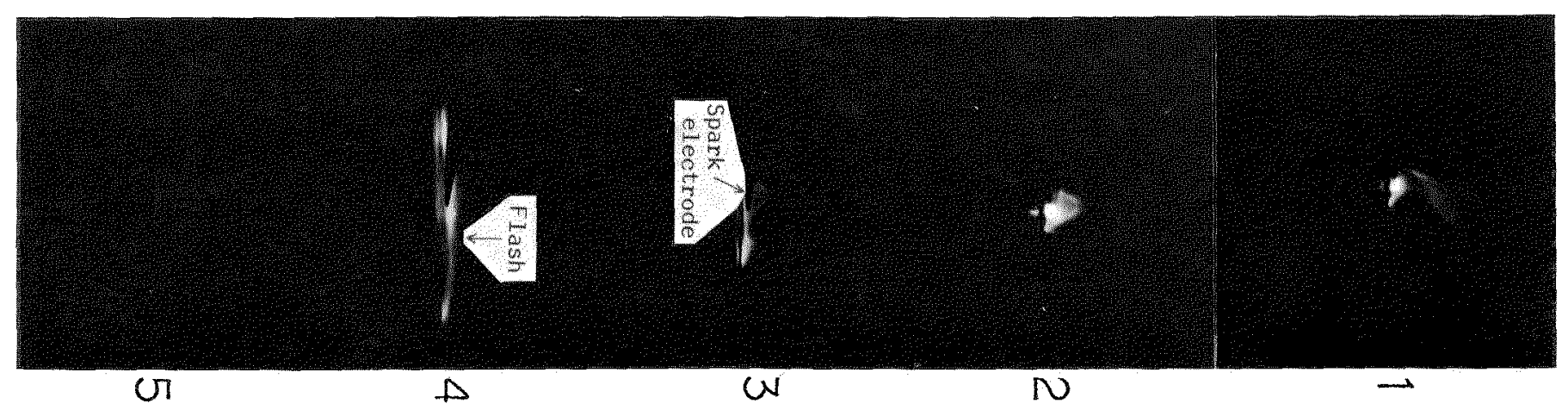

FICURE 6: Direct Movie Photographs (24 pps) at Flash Point $\left(38^{\circ} \mathrm{C}\right)$ of $\mathrm{n}$-Nonane, Spark Position is $3 \mathrm{~mm}$ above Pool. 




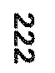

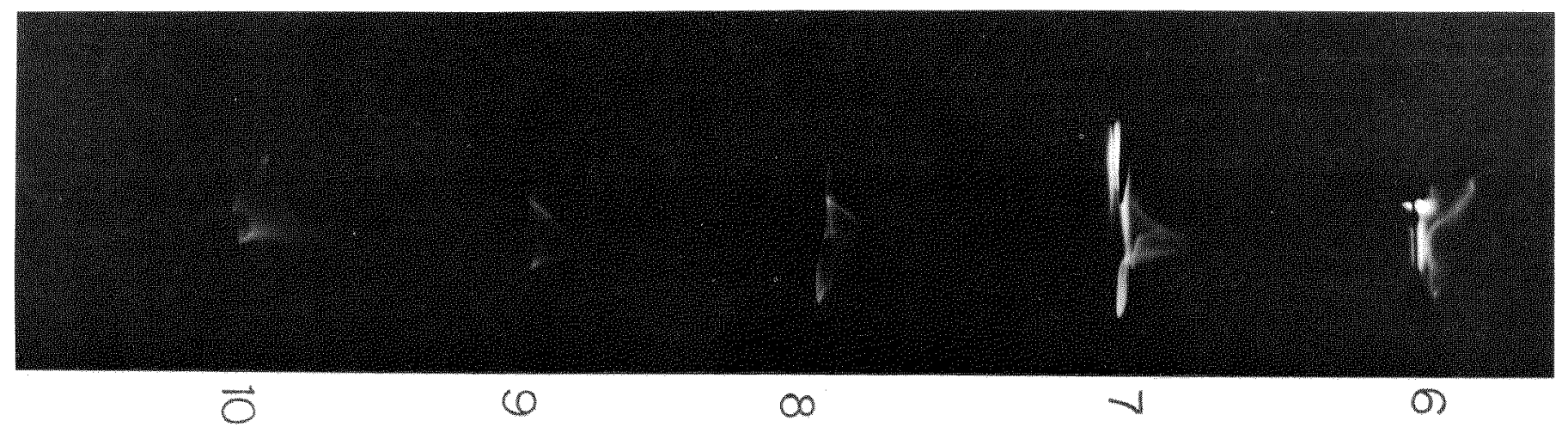

FIGURE 7: Direct Movie Photographs (24 pps) at Fire Point

$\left(42^{\circ} \mathrm{C}\right)$ of $\mathrm{n}$-Nonane, Spark Position is $3 \mathrm{~mm}$ above Pool. 
TABLE 1: Measured Fuel Temperatures at Pre-flash, Flash and Fire Phenomena with The Relation to The Height of Spark Electrode above Pool Surface.

\begin{tabular}{|c|c|c|c|c|c|c|c|c|c|c|c|c|c|}
\hline \multirow{2}{*}{ Eue1 } & \multicolumn{4}{|c|}{ Prewflash point $\left({ }^{\circ} \mathrm{C}\right)$} & \multicolumn{5}{|c|}{ Flash point $\left({ }^{\circ} \mathrm{C}\right)$} & \multicolumn{4}{|c|}{ Fire Point $\left({ }^{\circ} \mathrm{C}\right)$} \\
\hline & $A$ & B & c & D & A & B & $c$ & D & E & A & B & $\mathrm{c}$ & $\mathrm{D}$ \\
\hline n-Octane & 16.6 & 14.8 & 17.8 & $-m$ & 17.4 & 17.0 & 20.1 & 20.4 & 12 & 20.8 & 17.6 & 23.0 & 22.8 \\
\hline n-Nonane & 36.3 & 34.0 & 35.9 & 38.3 & 38.0 & 38.7 & 37.3 & 40.1 & 31 & 42.2 & 44.6 & 44.7 & 47.1 \\
\hline n-Decane & 51.0 & 51.0 & 56.4 & 55.3 & 53.6 & 52.1 & 58.2 & 59.1 & 46 & 60.6 & 62.4 & 64.2 & 65.2 \\
\hline $\mathrm{n}-\mathrm{C}_{4} \mathrm{H}_{9} \mathrm{OH}$ & - & 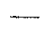 & - & - & - & - & $-\ldots$ & + & 29 & 38.1 & 42.9 & 44.7 & 48.7 \\
\hline iso- $\mathrm{C}_{4} \mathrm{H}_{9} \mathrm{OH}$ & יט- & - & - & - & - &  & $\longrightarrow$ & - & 28 & 28.8 & 32.3 & 35.7 & 38.5 \\
\hline o- $\mathrm{X}_{Y}$ lene & 34.3 & 34.5 & 34.6 & 34.5 & 36.9 & 35.9 & 38.8 & 39.0 & 32 & 41.5 & 48.2 & 50.1 & 51.0 \\
\hline
\end{tabular}

spark electrode position above liquid surface: $\lambda=3, B=5, C=7,0=9$ (trm) E : value from literature (closed cup method)

TABLE 2: Measured Flash and Fire Points by Tag Closed Cup and Pensky-Martens Methods.

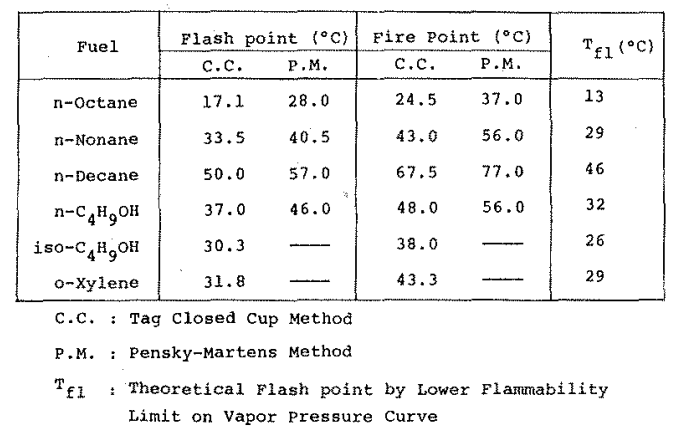

fuel pool where the flame can not propagate certainly exists. Glassman et al. reported that the quenching distance above liquid surface is very small (below $0.3 \mathrm{~mm}$ ) for some alcohols and very large (about $3 \mathrm{~mm}$ ) for some hydrocarbons (16). Therefore, from the different measuring methods of flash point and consequent different measured results as mentioned above, the significance and/or application of flash and fire points data to the investigation of such problems as flame spread mechanism across the liquid surface, ignition of liquid droplet and ignition hazard classification of liquid fuels should be discussed separately.

\section{PREDICTION OF FLASH POINT OF LIQUID FUEL MIXTURE}

It is well known that the lower and upper flammability limit concentrations of multicomponent fuel vapor mixture can be estimated approximately by Le Chatelier's law. There are, however, hypothetical limiting conditions in Le Chatelier's law as that each component in the vapor mixture has the same activation energy, and each activation probability which is proportional to the concentration has the same proportional constant.

For the liquid mixture, it is very difficult to estimate the flash point because the composition of vapor mixture above liquid surface varies with the liquid temperature, although the flammable limit concentration of the equilibrium vapor mixture above liquid pool at its certain temperature can be calculated by Le Chatelier's law. On the other hand, for multicomponent liquid mixtures such as kerosene and $\mathrm{JP}-4$, it has been suggested that the flash point is determined only 
by very small concentartion of dissolved highly volatile component $(10,21)$. In the present study, theoretical prediction of the flash point for the liquid fuel mixture in which each component has largely different volatility was tried.

Table 3 shows the flash points, by Tag Closed Cup method, of the mixtures of $n$-butanol and $n$-decane, and of $n$-heptane $\sim n$-dodecane with various mixing ratios, where the predicted flash points were determined by the partial vapor pressure of the most volatile component corresponding to the lower flammability limit concentration. It was assumed that the flash phenomenon is ascribed only to the most volatile component. As shown in the results, the predicted flash points by such the assumption are not necessarily valid, except that the mixture dissolves highly volatile component compared with other ones.

The flash point of the binary mixture of liquid fuels of the same kind, of which vapor pressures are largely different, can be calculated theoretically as follows, on the assumption that the liquid mixture is an ideal solution and then Raoult's law can be applied.

$$
p_{1}=r_{1} p_{1}, \quad p_{2}=r_{2} p_{2}\left(r_{1}+r_{2}=1\right)
$$

where, $P$ is the inherent vapor pressure of the component, $r$ is the mole fraction of the component in the liquid mixture, $p$ is the partial vapor pressure of the component in the equilibrium vapor mixture above liquid, and subscripts $I$ and 2 indicate the components 1 and 2 in the liquid mixture respectively.

Assuming that flash phenomenon is ascribed only to $p_{1}$, the partial vapor pressure of the more volatile and flammable component is estimated by ClausiusClapeyron's law as follows, although the total equilibrium vapor pressure of the liquid mixture is $p_{1}+p_{2}$.

$$
P_{1}^{*}=C \exp \left(-\frac{\Delta H_{1}}{R T_{1}^{*}}\right)
$$

For the temperature $T$ of the liquid mixture,

$\mathrm{p}_{1}=\mathrm{r}_{1} \mathrm{P}_{1}^{*}$ at $\mathrm{T}=\mathrm{T}_{1}^{*}, \quad \mathrm{p}_{1}=\mathrm{P}_{1}^{*}$ at $\mathrm{T}=\mathrm{T}_{1}^{*}+\Delta \mathrm{T}$

where, $\mathrm{P}_{1}^{*}$ is the vapor pressure corresponding to the lower flammability limit concentration, $T^{*}$ is the flash point of component $1, \Delta H_{1}$ is the latent heat of vaporization, $C$ Is the constant, $R$ is the gas constant, ${ }^{1} \Delta T$ is the elevation of flash point due to the solubilization of less volatile component 2 .

Consequently,

$$
C \exp \left(-\frac{\Delta H_{1}}{R T_{1}^{*}}\right)=r_{1} C \exp \left(-\frac{\Delta H_{1}}{R\left(T_{1}^{*}+\Delta T\right)}\right) \text { at } T=T_{I}^{*}+\Delta T \text {. }
$$

Therefore,

$$
\mathrm{T}_{1}^{*}+\Delta \mathrm{T}=\left(\frac{1}{\mathrm{~T}_{1}^{*}}+\frac{\mathrm{R}}{\Delta \mathrm{H}_{1}} \ln \mathrm{r}_{1}\right)^{-1}
$$

Fugure 8 shows the measured results of flash and fire points of the mixture of $n$-octane and $n$-decane, the calculated flash point is by the equation (4) where $n$-octane is the component 1 , and the predicted flash point is by the partial vapor pressure of n-octane corresponding to the lower flammability limit (1.0 vol\%) calculated by Raoult's law. As shown in these results, predicted flash point agrees well with the measured one if the volume fraction of n-decane is below about 0.7 , but the calculated flash point is reliable only at high fraction 
of n-octane. If more accurate expression of vapor pressure equation is taken (31), and/or the difference between the theoretical flash point ( $T_{f l}$ ) and the measured one by closed cup method can be reduced by the improved measurement, theoretical study on the flash point calculation will take long strides, which is the subject for future study.

TABLE 3: Measured Flash Points $\left(T_{f}\right)$ and Predicted Ones of the Fuel Mixtures with Various Mixing Ratios.

\begin{tabular}{|c|c|c|c|}
\hline Volumetric mixing xatio & \multicolumn{2}{|c|}{$\begin{array}{c}\text { Flash Point }\left({ }^{\circ} \mathrm{C}\right) \\
\text { (Closed cup) }\end{array}$} \\
\hline$n-\mathrm{C}_{4} \mathrm{H}_{9}$ OH & $\mathrm{n}-\mathrm{C}_{10}{ }^{\mathrm{H}} 22$ & $\mathrm{~T}_{E}$ & Predicted \\
\hline 1 & 1 & 34.0 & 35.5 \\
3 & 1 & 34.5 & 34.5 \\
1 & 3 & 34.5 & 40.7 \\
\hline
\end{tabular}

\begin{tabular}{|c|c|c|c|c|c|c|c|}
\hline \multicolumn{6}{|c|}{ Volumetric mixing ratio } & \multirow{2}{*}{\multicolumn{2}{|c|}{$\begin{array}{l}\text { Plash point }\left(^{\circ} \mathrm{C}\right) \\
\text { (Closed cup) } \\
\mathrm{T}_{\mathrm{E}} \mid \text { Predioted }\end{array}$}} \\
\hline $\mathrm{n}-\mathrm{C}_{7} \mathrm{H}_{26}$ & $n-\mathrm{C}_{8}{ }^{H} 18$ & $\mathrm{n}-\mathrm{C}_{9} \mathrm{H}_{2} \mathrm{O}$ & ${ }^{n-c_{10}{ }^{H}} 22$ & $n-c_{11}{ }^{11} 24$ & ${ }^{n-c_{12}} \mathrm{H}_{26}$ & & \\
\hline & & & 1 & 2 & 3 & 28.5 & 44.6 \\
\hline & & & 2 & 1 & 2 & 25.5 & 30.0 \\
\hline & 1. & 2 & 3 & 2 & 1 & 37.5 & 50.0 \\
\hline 1 & 1 & 2 & 3 & 2 & 1 & 24.3 & 34.0 \\
\hline
\end{tabular}



FIGURE 8: Flash and Fire Points of the Mixtures of n-0ctane and n-Decane with Various Mixing Ratios by Tag Closed Cup method, Prediction and Theoretical Calculation. 


\section{CONCLUDING REMARKS}

Above the pool surface of some liquid hydrocarbon fuels filled in the open cup, with spark ignition source in a quiescent atmosphere, "Pre-flash" phenomenon occurs at a little lower liquid temperature than the flash point. In pre-flash phenomenon, instantaneous faint but clear flamelet appears, and it propagates locally above pool surface,but is quenched on the way. Then, the scale of flame appearance above the liquid should be specified additionally in the usual methods of flash point measurement. The prediction of flash point of multicomponent liquid mixture by the partial vapor pressure of the most volatile and flammable component is not necessarily reliable, except the binary mixture. Comparing the calculated flash point of the binary hydrocarbon mixture by Clausius-Clapeyron's and Raoult's laws with the measured one suggested that the more accurate analysis of vapor pressure and the improvement of measuring method of the flash point are needed.

\section{ACKNOWLEDGMENT}

The authors express their sincere thanks to Mr. M. Kano for his great help in conducting the experiment. The authors wish also to acknowledge the help of drawing figures by $\mathrm{Mr}$. S. Aoyagi.

\section{REFERENCES}

1) J.H. Burgoyne and J.F. Richardson; Fuel, 28, 150 (1949).

2) J.H. Burgoyne and G. Williams-Leir; Fuel, 28,145 (1949).

3) J.B. Fenn; Ind. and Eng. Chemistry, 43, 2865 (1951).

4) R.M. Butler, et al.; Ind. and Eng. Chemistry, 48, 808 (1956).

5) W.A. Affens; 3. of Chem. and Eng. Data, 11, 197 (1966).

6) J.H. Burgoyne, et al.; J. of the Inst. of Petroleum, 53, 338 (1967).

7) S.S.Penner and B.P. Mullins; Explosions, Detonations, Flammability and Ignition (AGARDograph N0.31, Pergamon Press, 1959), Part II.

8) M.G. Zabetakis; U.S. Bureau of Mines Blletine, N0.627 (1966).

9) J.T. Dehn; Comb. and Flame, 24, 231 (1975).

10) W.A. Affens and G.W. McLaren; J. of Chem. and End. Data, 17, 482 (1972).

11) W.A. Affens, et al.; J. of Fire and Flammability, 8, 141, 1.52 (1977).

12) G.L. Nelson and J.L. Webb; ibid., 4, 210 (1973).

13) A.M. Kanury; Comb. Sci. \& Tech., 31, 297 (1983). 14) J.E. Anderson and M.W. Magyagi; ibid., 37, $193(1984)$. 15) K. Akita; Proc. of 14th Symp. on Comb.(Int'1) 1075 (1972). 16) I. Glassman and F.L. Dryer; Fire Safety J., 3,123 (1980/81).

17) H. Ishida and A. Iwama; Comb. Sci. \& Tech., 36, 51 (1984).

18) J.H. Burgoyne, et al.; Proc.Roy.Soc., A308, 39, 55, 69 (1968).

19) A.F. Roberts and B.W. Quince; Comb. and Flame, 20, 245 (1973).

20) A.F. Roberts; Proc. of 15 th Symp. on Comb. (Int'1) 305 (1974).

21) J.T. Bryant; Comb. Sci. \& Tech. 10, 185 (1975).

22) M.M. EL-Wakil and M.I. Abdou; Fuel, 45, 177, 188, 199 (1966).

23) G.S. Scott, et al.; Analytical Chem., 20, 238 (1948).

24) L. Delfosse, et al.; Comb. and Flame, 54, 203 (1983).

25) Z. Tamura and Y. Tanazawa; Proc. of 7th Symp. on Comb. (Int'1), 509 (1958).

26) W-J Yang; Inst. of Space \& Aeronaut.Sci. Univ.of Tokyo Report, 535 (1975).

27) I. Liebman, et al.; Comb.Sci.\& Tech., 1, 257 (1970). 28) C.C. Feng, et al.; Ibid., 10, 59 (1975). 29) M. Kaptain and C.E. Hermance; Proc. of 16th Symp. on Comb.(Int'1), 1295 (1976). 30) T. Hirano, et al.; ibid., 1307 (1976).

31) R.C. Reid, J.M. Prausnitz, T.K. Sherwood; The Properties of Gases and Liquids, 3rd ed., (McGraw-Hill, New York, 1977). 